\title{
Recent Developments in Solar Refrigeration Technology - A Review
}

\author{
Yogesh Musale $^{{ }^{*}}$, Satyawant Patil ${ }^{\dagger}$, Bhakti Chougule ${ }^{\dagger}$, Amruta Kulkarni $^{\dagger}$ and Ashish S. Utage $^{\dagger}$ \\ †Department of Mechanical Engineering, MIT College of Engineering, Kothrud, Pune, India
}

Accepted 02 March 2016, Available online 15 March 2016, Special Issue-4 (March 2016)

\begin{abstract}
The major problem in the country at present is the lack of electrification to provide refrigeration. Another option is erratic power also results in significant operating costs due to use of fossil fuels such as diesel. The thermal fossil fuel driven refrigeration system has a general efficiency of about 35\% on average and leads to large volumes of greenhouse gas emissions. This review is related to advances in solar refrigeration in which $\mathrm{Li}-\mathrm{Br}$ and $\mathrm{H}_{2} \mathrm{O}$ is best suitable pair for the absorption refrigeration process. Also refrigerant $\left(\mathrm{H}_{2} \mathrm{O}\right)$ has zero ozone depletion potential and very low global warming potential. Thus the refrigerator is eco-friendly. There are no moving parts involved in the system. In India average insolation is $5.5 \mathrm{~kW} / \mathrm{m} 2 /$ day over nearly $60 \%$ of the landscape which is most abundant, non-polluting source for the operation of such facilities. Hence this review emphasizing on employing renewable energy sources like solar energy in refrigeration system.
\end{abstract}

Keywords: Solar energy, Absorption refrigeration

\section{Introduction}

Space cooling and refrigeration are highly energy intensive processes. Cooling demands in various sectors are maximum mainly during day time when solar energy is also prevalent; this is more so in the hot summer season. Most parts of India get abundant sunshine throughout the year. Solar cooling/refrigeration is, therefore, the most relevant application for our country, especially in view of the rapidly increasing demand for energy and shortage of electric power. It is estimated that cooling consumes about 35,000 MW of electricity for various end-uses. Part of this is from conventional power plants in areas where electricity is easily available and the rest is being generated through DG sets which consume a significant amount of highly subsidized diesel leading to noise and air pollution, besides heavy $\mathrm{CO}_{2}$ emissions. Apart from this, in rural areas, where such options are not available, $30-40 \%$ of agricultural produce is being destroyed due to lack of proper post-harvest cooling facilities. Thus, resorting to solar cooling not only mitigates energy shortage and environmental pollution, but also contributes to the reduction of food spoilage. The applications of cooling include domestic refrigeration, comfort/ space cooling in various sectors, industrial refrigeration and process cooling, cold storages with deep freezing, vaccine storages in PHCs, etc. The capacity range of systems varies from a few Watts to thousands of kW. Solar cooling/airconditioning systems have the potential to catering to

*Corresponding author: Yogesh Musale all the above sectors. However, this is an emerging technology and faces many growth barriers, which are different from other heating and cooling technologies. The solar cooling technologies are mainly classified into two main groups depending on the energy supply: a thermal/work driven system and electricity (Photovoltaic) driven system. Each group can be classified as the following:

1) Thermal/work driven system

- Absorption refrigeration cycle

- Adsorption refrigeration cycle

- Desiccant cooling cycle

- Ejector refrigeration cycle

2) Electricity (Photovoltaic) driven system

- Vapour compression refrigeration cycle

- Thermo-electric refrigeration cycle

- Stirling refrigeration cycle

\section{Literature Review}

$\mathrm{V}$ Mittal et. al studied an air-conditioning system utilizing solar energy would generally be more efficient, cost wise, if it was used to provide both heating and cooling requirements in the building it serves. This paper will gives fundamental knowledge on a solar absorption cooling systems with the absorption pair of lithium bromide and water. They also studied the influence of key parameters on the overall system performance. According to them solar absorption air-conditioning has the advantage of both 
the supply of sunshine and the need for refrigeration to reach maximum levels in the same season. Of the two main technologies of solar cooling systems namely, solar thermal technology and solar cooling technology, the emphasis in this paper is placed on solar cooling technology.

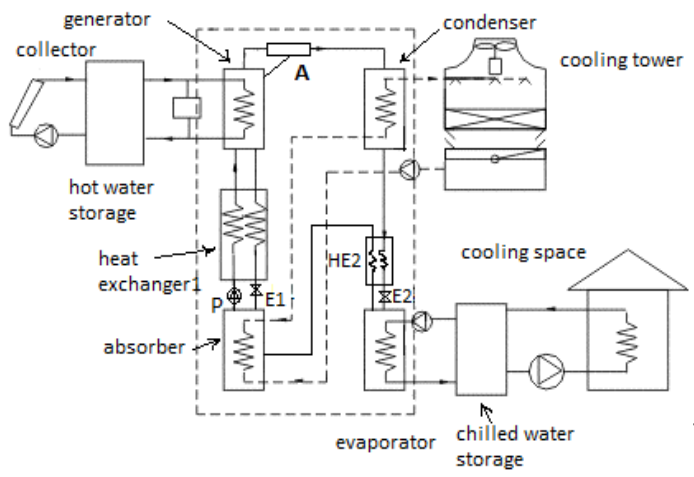

Fig 2.1 solar absorption air-conditioning

The main process taking place in the chiller is as follows (as shown in Figure 2.2).

- Line 1-7: The weak solution from the absorber at point 1 is pumped through the heat exchanger to the generator; point 7 indicates the properties of the solution at the outlet of the heat exchanger. During the process $1-7$, the concentration of the weak solution is held constant.

- Line 7-2-3: Process 7-2 shows the sensible heating of the weak solution in the generator, and 2-3 indicates the boiling of water vapour from the solution at the constant condensing pressure Pc (although the boiling pressure is a little higher than the condensing pressure, the difference is negligible). During this process, the weak solution becomes a strong solution.

- Line 3-8: Symbolizes the strong solution passing to the absorber through the heat exchanger, in which it preheats the weak solution flowing from the absorber to the generator. During this process, the concentration of the strong solution is constant. Where,

Te-Evaporator temp.

Ta-Absorber temp.

Tc-Condenser temp.

Tg-Generator temp.

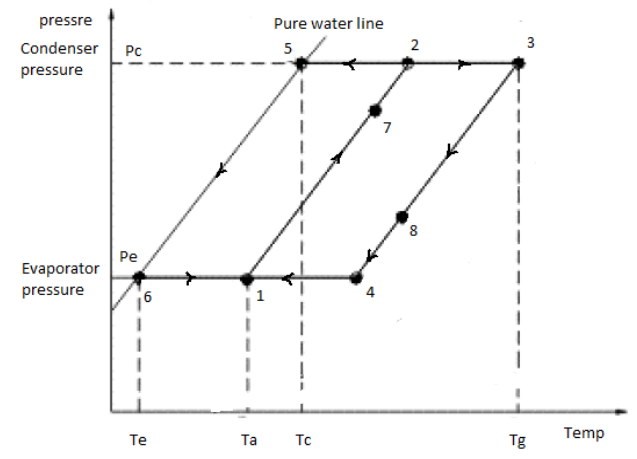

Fig 2.2 Process diagram of solar VAS
- Line 8-4-1: Indicates the idealized process of absorption of water vapour from the evaporator by the strong solution in the absorber.

- Line 2-5: Denotes the condensation of water vapour in the condenser by the cooling water from the cooling tower, at constant condensing pressure Pc.

- Line 5-6: Shows the flow of condensed water from the condenser to the evaporator.

- Line 6-1: Indicates the evaporation of the water in the evaporator due to the prevailing low pressure Pe. Also, the water absorbs the heat from the space to be cooled. The water vapour from the evaporator is, in turn, absorbed by the strong solution in the absorber, thus completing the cycle of refrigeration.

Some of the findings of this paper are as follows:

- Among the major working pairs available, LiBr- H2O is considered to be better suited for solar absorption air-conditioning applications. $\mathrm{LiBr}$ - H2O pair has higher COP than any other pair of the working fluids - Generator inlet temperature of the chiller is the most important parameter in the design and fabrication of a solar powered air-conditioning system.

- A Single effect system with refrigerant storage has the advantage of accumulating refrigerant during the hours of high solar insolation but the double effect convertible system has a higher overall COP.

- A Two-stage system has the advantage of lowering the generator temperature, which provides the use of conventional flat plate collectors, thereby bringing down the cost of the system.

V. K. Bajpai et. al focused on design and study an environment friendly vapour absorption refrigeration system of unit capacity using R 717 (NH3) and water as the working fluids. The basic idea of this paper is derived from the solar heating panel installed on the hostel roofs of the institute. They designed the following a solar absorption refrigeration system.

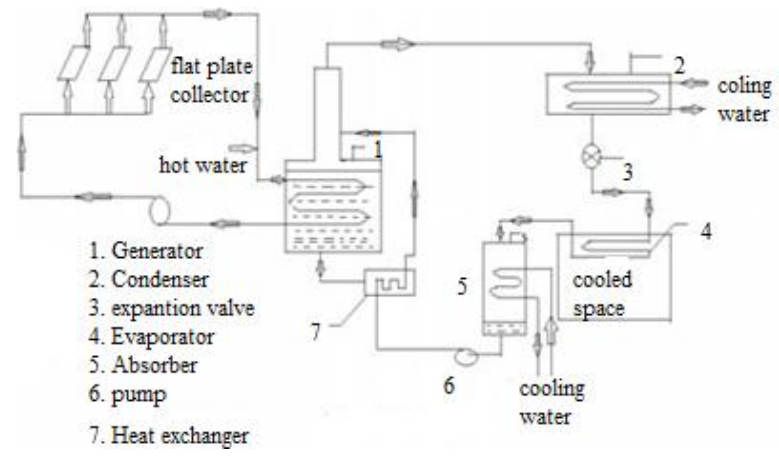

Fig 2.3 layout of Solar absorption refrigeration system

They calculated the heat input required to run the $1 \mathrm{TR}$ vapour refrigeration system is about $304.2 \mathrm{KJ} / \mathrm{min}$. This heat in the generator is supplied by the hot water 
coming from the solar flat plate water heater. For this system the coefficient of performance is also calculated. The results can be summarized as:

- Mass flow rate of cold water $=3 \mathrm{Kg} / \mathrm{min}$

Designed operating conditions:

- Condenser pressure: 10 bar

- Evaporator pressure: 1 bar

- Heat input required (at generator) $=304.2 \mathrm{KJ} / \mathrm{min}$

- Area of the solar collectors required $=24$ square meter i.e. 4 plates of $3 \times 2 \mathrm{~m}^{2}$ can be used.

- Output temp of water from solar heater $=84{ }^{\circ} \mathrm{C}$

- COP of refrigerating unit $=0.69$

- COP of the whole system $=0.58$

From above results, he has been proved the feasibility of the solar powered vapour absorption refrigeration system.

Lim Chin Haw et al. studied an air-conditioning system which is the dominant energy consuming appliances in most of today office buildings. Today most of the small office buildings deployed conventional cooling technologies (VCR) that exhibits high energy consumption, high electricity peak loads demand and in general it employ refrigerants which have several negative impacts on the environment. Because of the high energy cost, the decrease of fossil fuel resources and the rise of environmental pollution. Hence they utilized the low level renewable energy sources such as solar energy in refrigeration systems. In this paper they provided technical overview and economic feasibility of a solar assisted air conditioning system.

In this study absorption chiller is used having 23 kW capacity and 0.7 C.O.P. They found that solar assisted air conditioning based on small absorption chiller is suitable for small office. It leading to save remarkable electricity and reduces the environmental impact especially the reduction of $\mathrm{CO} 2$ from the environment. It is vital to maximize the application of the solar thermal energy by not only as driving heat source for the absorption chiller but also providing hot water supply to the users. With both of this usage, the economic viability of solar assisted air conditioning system can be further optimized. Although solar assisted air conditioning system has a high capital investment but with a payback period of 8 years, it has made this technology a viable investment for both the client and the developer of a small office building development.

Ashwin Philip Kurian et. al reported the absorption refrigeration system. The absorption refrigeration system catering to a load of $1.2 \mathrm{~kW}$ running at a lower temperature level of -4 Deg $C$ requiring about $2.4 \mathrm{~kW}$ of heat input to the bubble pump and generator. The system required a high performance vacuum tube solar thermal collector with $6.4 \mathrm{~m}^{2}$ of absorber area with COP approaching 0.5 when heat output at the condenser and absorber was closer to 55 Deg C. This was to cater to $500 \mathrm{~kg}$ of fruit and vegetable in a floor are of $12 \mathrm{~m}^{2}$. It came equipped with an ice battery bank of $6 \mathrm{kWh}$. This required a much higher temperature for the generation and bubble pumping thermal input however at nearly 190 Deg C.

N. Hatraf et al. studied the effect of external and operating conditions on a solar Lithium Bromide absorption chiller.

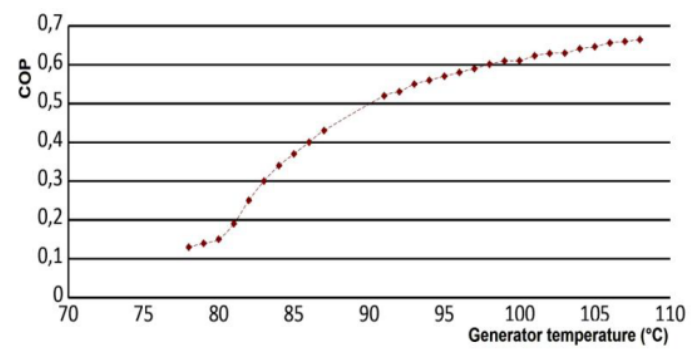

Graph 2.1 Effect of the generator temperature on COP

The coefficient of performance COP depends on generator temperature, as shown in the Graph 2.1, more we increase the boiling temperature, the separation of the water vapors occurs easily and consequently we increase the effectiveness of the absorption chiller however the generator inlet temperature could not be increased too much because of the crystallization of the $\mathrm{LiBr}$.

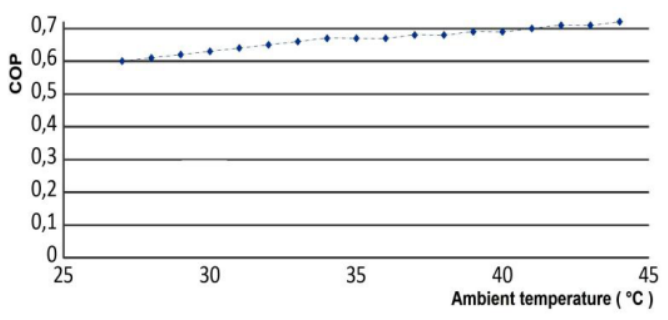

Graph 2.2 Effect of ambient temperature on COP

The ambient temperature has a negligible effect on the COP of the chiller, because of the use of water as cooling fluid.

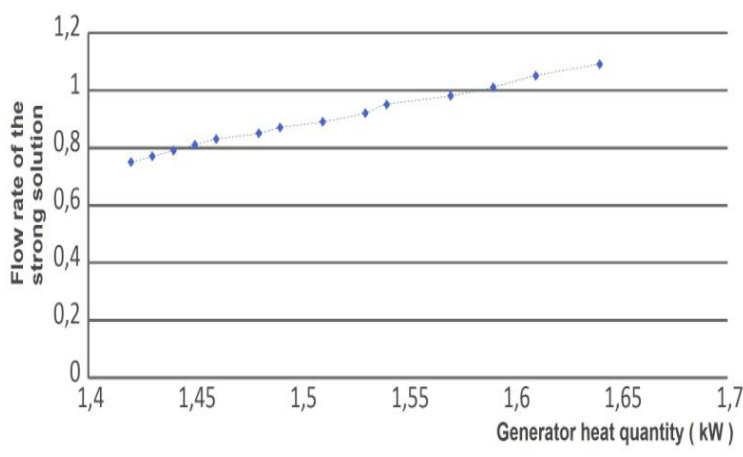

Fig. 2.3 Effect of the generator heat quantity on flow rate of the strong solution

According to the exposed results, they concluded that $\mathrm{LiBr} /$ water absorption chiller is more convenient than other couple for the same capacity, it doesn't depends 
on many factors if we use cooling water condenser, air cooling condenser system is affected by ambient temperature which fluctuates along the day. The generator temperature is an important factor to design an effective absorption chiller, by taking into account the crystallization of the LiBr.

T. Srinivas et. al developed cogeneration plant by coupling a Kalina cycle system (KCS) with a vapor absorption refrigeration (VAR) system. The working fluid used in this theoretical thermodynamic evaluation is ammonia water mixture. A low temperature heat recovery $\left(150{ }^{0} \mathrm{C}-200{ }^{\circ} \mathrm{C}\right)$ from engine exhaust gas, solar collectors, or similar can be used to operate the plant. A controlling facility is provided to set the required amount of power or cooling to meet the variable demand. In this proposed plant, the liquid refrigerant absorbs more amount of heat from evaporator surroundings with a flow control located in between power and cooling cycles. The extra included components are condenser, heat exchanger and throttling device over KCS plant. Due to possibility of more cooling, it offers high energy utilization factor (EUF).

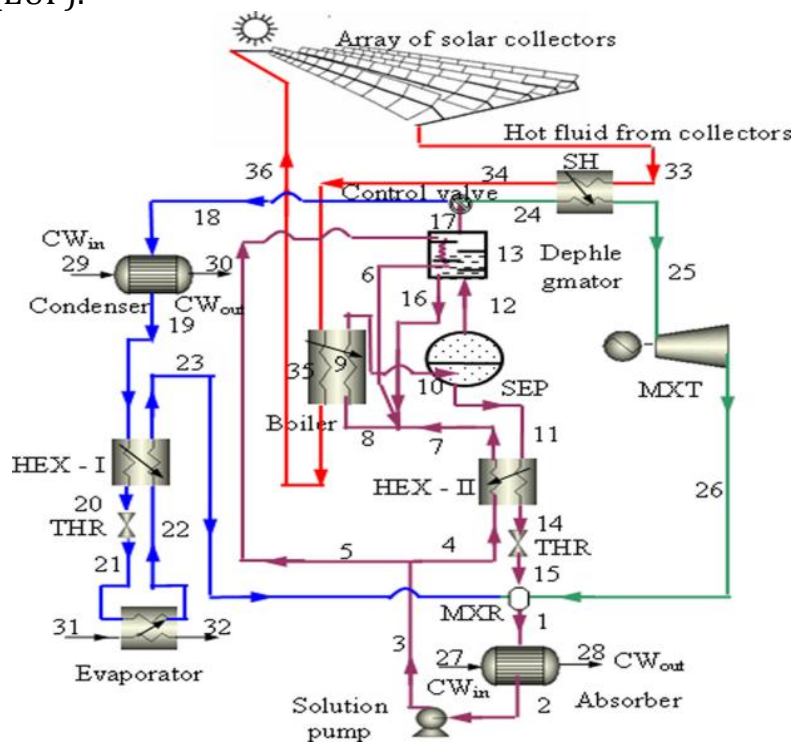

Fig 2.4 Cogeneration Kalina cycle system (KCS) with a vapor absorption refrigeration (VAR) system

The coupled plant characteristics are studied with changes in mass split ratio, separator vapor fraction, separator temperature, and turbine concentration to develop efficient working conditions. The power mass split ratio is varied from $80 \%$ to $100 \%$ to run the coupled plant at nearly full load conditions. The separator vapor fraction and temperature are optimized at $45 \%$ and $150{ }^{\circ} \mathrm{C}$, respectively. It is recommended to maintain the turbine concentration above 0.85 for optimum power and cooling. The maximum cycle EUF and plant EUF are 0.15 and 0.06 , respectively, at $80 \%$ power mass split ratio. The specific power and specific cooling at these conditions are $62 \mathrm{~kW} / \mathrm{kg}$ and $72 \mathrm{~kW} / \mathrm{kg}$, respectively.

\section{Conclusions}

With regard to the lack of reliable power, the rising price of fuel and lack of electrification the use of renewable forms of energy, solar energy is ideal due to its geographical spread across the entire country round the year. Of the heat driven refrigeration cycles, vapour absorption refrigeration systems were deemed ideal for the Indian rural scenario due to high solar insolation levels throughout the country. We can use waste heat from solar power production or ample bio mass and farm waste to run the thermal requirements even in the absence of sunlight. Among the major working pairs available, $\mathrm{LiBr}-\mathrm{H}_{2} \mathrm{O}$ is considered to be better suited for solar cold storage because of higher coefficient of performance.

The machines generally utilize environmentally friendly refrigerant water which has no greenhouse potential. Because the systems merely require auxiliary energy for the operation of pumps and heat rejection they utilize significantly less power (or no other power). Solar machines have few moving parts and a long life if designed correctly. The electricity grid is also relieved, since the mass operation of electrical airconditioners in summer occasionally leads to severe strain on the electricity grid. In addition to cooling, the solar collector system can also provide thermal energy for domestic hot water preparation and heating support which leads to a further reduction of emissions. Furthermore, noise emissions are significantly lower since machines work without compressors.

A variety of products are stored in these refrigerated warehouses, depending on the product characteristics and storage requirements.

\section{References}

V Mittal (2005), The study of solar absorption airconditioning systems, Journal of Energy in Southern Africa, Vol 16, No.- 4, pp. 59-66.

V. K. Bajpai (2012), Design of Solar Powered Vapour Absorption System, Proceedings of the World Congress on Engineering, London, U.K, Vol III.

N. Hatraf (2014), The effect of external and operating conditions on a solar Lithium Bromide absorption chiller, Revue des Energies Renouvelables, Vol. 17, pp 301 - 308

Ashwin Philip Kurian (2012), An Investigation into Solar Refrigeration Technology And Its Application, A thesis submitted for degree Master of Science Sustainable Engineering: Renewable Energy Systems and the Environment,

T. Srinivas (2014), Thermal Optimization of a Solar Thermal Cooling Cogeneration Plant at Low Temperature Heat Recovery, Journal of Energy Resources Technology, June, Vol.136.

Project report on cold chain by Madhya Pradesh Warehousing corporation.

Lim Chin Haw, An Overview of Solar Assisted AirConditioning System Application In Small Office Buildings In Malaysia, Proceedings of The 4th IASME / WSEAS International Conference On Energy \& Environment, pp $244-25$ 